\title{
Inhibition Effect of Phthalocyaninatocopper(II) and 4- Tetranitro(phthalocyaninato)copper(II) Inhibitors for Protection of Aluminium in Acidic Media
}

\author{
Thabo Pesha ${ }^{1}$, Gobeng R. Monama ${ }^{1}$, Mpitloane J. Hato ${ }^{1, *}$, Thabiso C. Maponya ${ }^{1}$, Mamookgo E. \\ Makhatha $^{2}$, Kabelo E. Ramohlola ${ }^{1}$,Kerileng M. Molapo ${ }^{3}$, Kwena D. Modibane, ${ }^{1, *}$, Mary S. Thomas $^{1}$ \\ ${ }^{1}$ Department of Chemistry, School of Physical and Mineral Sciences, Faculty of Science and \\ Agriculture, University of Limpopo (Turfloop Campus), Polokwane, Sovenga 0727, South Africa \\ 2 Department of Metallurgy, School of Mining, Metallurgy and Chemical Engineering, Faculty of \\ Engineering and Built Environment, University of Johannesburg (Doorfontein Campus), Johannesburg \\ 2001, South Africa \\ ${ }^{3}$ Department of Chemistry, Faculty of Natural Science, University of the Western Cape (Bellville \\ Campus), Cape Town 7535, South Africa \\ *E-mails: kwena.modibane@ul.ac.za; mpitloane.hato@ul.ac.za
}

doi: $10.20964 / 2019.01 .17$

Received: 4 January 2018 / Accepted: 3 October 2018 / Published: 30 November 2018

The inhibition effect of phthalocyaninatocopper(II) (CuPc) and 4-tetranitro(phthalocyaninato)copper(II) $(\mathrm{TNCuPc})$ on aluminium in $1 \mathrm{~mol} / \mathrm{L} \mathrm{HCl}$ was investigated by electrochemical techniques. The $\mathrm{CuPc}$ and TNCuPc inhibitors were synthesized and confirmed by using X-ray diffraction (XRD), Fourier transform infrared (FTIR), simultaneous thermal analysis (STA, thermogravimetric analysis (TGA)/differential scanning calorimetry (DSC)) and ultraviolet-visible spectroscopy (UV-vis). The XRD, UV-vis and FTIR analyses showed successful formation of $\mathrm{CuPc}$ and TNCuPc inhibitors. The thermal stability of CuPc increased upon the introduction of $\mathrm{NO}_{2}$ group in the peripheral position as indicative of the formation of TNCuPc. The potentiodynamic polarization (PDP) curves of aluminium in the corrosive environment of $\mathrm{HCl}$ in the presence and absence of $\mathrm{CuPc}$ and $\mathrm{TNCuPc}$ compounds demonstrated that both cathodic and anodic processes of $\mathrm{Al}$ corrosion were suppressed. The Nyquist plots of electrochemical impedance spectroscopy (EIS) expressed mainly as a capacitive loop with different concentrations of $\mathrm{CuPc}$ and TNCuPc. The inhibition efficiency of these inhibitors increased with increase in inhibitor concentration, and their inhibition efficiencies in the same concentration decreased in the order of $\mathrm{CuPc}>\mathrm{TNCuPc}$ according to PDP and EIS results due to a steric hindrance.

Keywords: Phthalocyaninatocopper(II); 4-tetranitro(phthalocyaninato)copper(II); corrosion inhibitor; aluminium; electrochemical measurements 


\section{FULL TEXT}

(C) 2019 The Authors. Published by ESG (www.electrochemsci.org). This article is an open access article distributed under the terms and conditions of the Creative Commons Attribution license (http://creativecommons.org/licenses/by/4.0/). 